\title{
Educação Física e trabalho: considerações a respeito da inserção profissional de egressos da FEF-UFG
}

CDD. 20.ed. 370.7

796

http://dx.doi.org/10.1590/1807-55092015000200325
Roberto Pereira FURTADO* Lorena Paes SANTIAGO*
*Faculdade de Educação Física e Dança, Universidade Federal de Goiás.

\section{Resumo}

Este estudo teve o objetivo de analisar a inserção inicial de egressos da Faculdade de Educação Física da Universidade Federal de Goiás em campos de intervenção profissional. Obtivemos resposta de 46 questionários distribuídos para egressos das turmas de Licenciatura em Educação Física, concluintes em 2008, 2009 e 2010, que são as três primeiras turmas formadas após revisão curricular. A partir desta pesquisa percebemos contradições entre as expectativas profissionais anteriores e posteriores à formação inicial. Identificamos a escola e a academia de ginástica como principais locais de trabalho dos egressos. Apesar de estarem no início de suas carreiras, muitos já se encontram desestimulados com as condições de trabalho. No entanto, alguns ainda vislumbram possibilidades de desenvolvimento na carreira, tanto pela melhoria das condições de trabalho no campo de intervenção quanto pela inserção profissional no ensino superior.

Palavras-Chave: Carreira; Atuação profissional; Escola; Academia de ginástica.

\section{Introdução}

A escolha pelo campo de atuação profissional é resultado de múltiplas determinaçóes, dentre elas, a formação inicial é parte importante. Porém, ao mesmo tempo, o campo de atuação profissional não é simplesmente resultado de uma escolha, mas também, de condiçôes e oportunidades encontradas pelo egresso no mercado de trabalho.

Algo que acompanha a inserção em determinado campo profissional é a expectativa de construção de uma carreira, compreendida como "a trajetória dos indivíduos através da realidade social e organizacional das ocupaçôes [...] consiste em uma seqüência de fases de integração em uma ocupação e de socialização na subcultura que a caracteriza"1 (p.225).

Entretanto, é em uma lógica de organização do mundo do trabalho característica dos tempos áureos da sociedade salarial ou do fordismo ${ }^{2}$ que a construção da carreira profissional aparece como uma possibilidade e expectativa dos trabalhadores. A sociedade salarial pode ser caracterizada a partir de uma "poderosa sinergia entre o crescimento econômico, com seu corolário, o quase-plenoemprego, e o desenvolvimento dos direitos do trabalho e da proteção social"’3 (p.493). Após esse período, na fase de acumulação flexível do capital, fica comprometida a concepçáo de construçáo de carreira ${ }^{4}$.

A relevância de tal discussão, ainda pouco aprofundada no campo da Educaçáo Física, está principalmente relacionada com a necessidade constante de reflexóes a respeito da relação entre a formação e o mundo do trabalho. As reflexōes que envolvem a formação e o trabalho no campo da Educação Física são bastante fecundas e polêmicas. Podemos citar como emblemas desta característica do campo o recente processo de regulamentação da profissão, a recente divisão da formação entre Licenciatura e Bacharelado, com os debates que os acompanham, além da fecunda discussão ocorrida principalmente nos anos 1980 a respeito da identidade da Educação Física, que também permeava principalmente a relação entre a formaçáo e o trabalho. Neste sentido, é fundamental o desenvolvimento de pesquisas empíricas que busquem de alguma forma contribuir com as reflexóes a cerca desta relação a partir de análises da própria realidade encontrada pelos egressos na construção de sua carreira profissional. É com esta expectativa que apresentamos os resultados desta pesquisa que, em um âmbito mais específico, podem contribuir principalmente com as 
discussóes internas da Faculdade de Educação Física da UFG a respeito do seu projeto de formação.

É importante ressaltar que há no campo da Educação Física brasileira um debate em andamento a respeito das possibilidades legais de atuação profissional dos licenciados. Há aqueles que defendem e interpretam que as diretrizes curriculares para a formação em Educação Física restringem também o campo de trabalho. De acordo com essa interpretação, as Diretrizes Curriculares Nacionais e Resoluções elaboradas pelo MEC teriam abrangência além da regulamentação da formação e, assim, determinariam também campos de trabalho para as profissóes.

Por outro lado, há interpretaçóes de que o estabelecimento de diretrizes para a formação profissional não significa restrição de espaço no mercado de trabalho. Tal restrição, de acordo com o artigo $5^{\circ}$ da Constituiçáo Federal, poderia ser estabelecida apenas por meio de Lei Federal. Nesse sentido, a LDB legisla sobre a obrigatoriedade de formação em Licenciatura para o profissional da educação básica. Porém, não há nenhuma outra Lei Federal que impeça o licenciado em Educaçáo Física ou o licenciado em qualquer outra área de conhecimento de trabalhar em espaços não diretamente vinculados com a educação básica. Tal polêmica é objeto de debates do ponto de vista da formação, do trabalho e do direito trabalhista. No Estado de Goiás, bem como em outros Estados brasileiros, está garantida ao licenciado em Educação Física, por decisão judicial ${ }^{2}$, a possibilidade de atuação profissional em campos de trabalho que não seja a educação básica. Além disso, há diversos pareceres do Conselho Nacional de Educaçáa ${ }^{b}$ com a tentativa de esclarecer a questáo.

A Faculdade de Educação Física da Universidade Federal de Goiás, desde seu primeiro currículo de formação em Licenciatura em Educaçáo Física, tem optado politicamente pela construção de um currículo que tenha o foco na formaçáo para a educaçáo básica. Essa característica não mudou após a LDB e as novas Resoluçôes que regulamentaram a formação de licenciados. Porém, seus egressos também tem tido reconhecimento e conquistado a legitimidade para o trabalho em campos diferentes da educação básica, como permitido por Lei. Mas com o intuito de oferecer uma formação mais específica para aqueles interessados em desenvolver seus estudos em espaços que não sejam da educaçáo formal, a Instituiçáo optou por criar um curso de Bacharelado em Educação Física que teve início no ano de 2009.

O problema que motivou o desenvolvimento desta pesquisa pode ser sintetizado com a pergunta: como os egressos da FEF-UFG do curso de Licenciatura em Educação Física estão se inserindo no mercado de trabalho e qual a expectativa de construção da carreira que eles apresentam? Esta problemática inicial conduziu nossas reflexóes e delimitamos a pesquisa na forma de um estudo de caso com o objetivo de analisar a inserçáo no trabalho dos egressos de Educação Física da Universidade Federal de Goiás (FEF/ UFG), das turmas formadas em 2008, 2009 e 2010 e as suas expectativas com a carreira profissional.

\section{Método}

O estudo foi desenvolvido a partir de uma perspectiva descritiva que tem como objetivo descrever as características de um determinado grupo estabelecendo relaçóes entre variáveis conforme explica $\mathrm{GIL}^{5}$. No entanto, o mesmo autor afirma que determinadas pesquisas além de descrever, buscam analisar a natureza destas relaçóes e proporciona uma nova visão do problema, dando indicações para próximos estudos tal como ocorre na pesquisa exploratória.

Para a coleta de dados, foi utilizado um questionário contendo 19 questóes mistas entre fechadas e abertas, que foi anteriormente testado com um grupo piloto. A população do estudo constituiu-se dos egressos da FEF-UFG a partir da primeira turma formada no regime semestral, aquelas que concluíram o curso de Licenciatura em 2008, 2009 e 2010. A amostra derivou da disponibilidade de participação dos egressos que após contato por e-mail ${ }^{c}$ devolveram o questionário.

O período de coleta de dados compreendeu os meses de junho, julho e agosto de 2011, totalizando 46 participantes, sendo 63\% mulheres e 37\% homens. A faixa etária dos participantes varia entre 21 e 37 anos. A maioria dos participantes reside no Estado de Goiás, especialmente na capital Goiânia (72\%). Sendo que $17 \%$ deles moram em outras cidades do Estado; 4\% na capital federal; 7\% em outros Estados. Aproximadamente 90\% trabalham nas mesmas cidades em que residem.

A análise dos dados seguiu uma orientação quantitativo-qualitativa. A pesquisa qualitativa trata do "universo de significados, motivaçôes, aspiraçôes, crenças, valores e atitudes, o que corresponde a um 
espaço mais profundo das relações, dos processos e dos fenômenos"6 (p.21-2).

Para a análise dos dados qualitativos, optamos pela técnica de análise de conteúdos ${ }^{7}$ das respostas às questôes abertas do questionário. Em relação aos dados

\section{Resultados e discussão}

\section{A inserção inicial dos egressos nos campos de trabalho}

Compreendemos que o professor de Educação Física trabalha com os temas da cultura corporal dentre eles, destacam-se no atual momento histórico o esporte, a ginástica, as lutas, a dança, os jogos e as brincadeiras. Os principais campos de trabalho do professor de Educação Física são aqueles diretamente relacionados com a educação formal, com a saúde, com o lazer ou com a iniciação e treinamento esportivo. Em quaisquer desses campos, o professor quantitativos, foram utilizados elementos da estatística básica, como a média e o percentual, para a análise das questôes objetivas do questionário e de algumas das respostas às perguntas abertas que, após a análise de conteúdos, puderam ser objetivadas em categorias.

TABELA 1 - Campos de atuação profissional.

de Educação Física utiliza-se de conteúdos da cultura corporal produzida e desenvolvida historicamente pela humanidade. Assim também se organiza o currículo da FEF-UFG, pois considera que a intervenção profissional e o campo acadêmico da Educação Física podem ser subdivididos em quatro grandes núcleos temáticos: saúde, esporte, educação e lazer.

A TABELA 1 nos auxilia na identificação dos locais onde atualmente trabalham os egressos pesquisados. Os dados TABELA 1 foram organizados a partir da análise de conteúdo de uma questão aberta do questionário.

\begin{tabular}{cccccccc}
\hline \multicolumn{7}{c}{ Local de trabalho atual } \\
\hline & Escola & Saúde & $\begin{array}{c}\text { Outros relacionados } \\
\text { com a EF }\end{array}$ & $\begin{array}{c}\text { Bolsista de } \\
\text { Mestrado }\end{array}$ & $\begin{array}{c}\text { Ensino Superior } \\
\text { (EAD) }\end{array}$ & $\begin{array}{c}\text { Náo relacionados } \\
\text { com a EF }\end{array}$ & Desempregado \\
\hline $\mathrm{N}$ & 20 & 14 & 8 & 3 & 4 & 12 & 1 \\
$\%$ & $32 \%$ & $22 \%$ & $13 \%$ & $5 \%$ & $6 \%$ & $20 \%$ & $2 \%$ \\
\hline
\end{tabular}

O número superior ao quantitativo de participantes $(n=46)$ se deve à possibilidade de respostas múltiplas.
Podemos perceber que a maioria dos participantes da pesquisa atua na educação formal como professores de Educação Física e/ou dança em escolas públicas e particulares ${ }^{\mathrm{d}}$. Também há incidência de trabalho no ensino superior, por meio da Educação à Distância (EAD). Apesar da ampliação dos campos de trabalho da Educação Física ${ }^{8-9}$, a escola se apresentou como principal lócus de atuação de grande parte dos egressos do curso de Educação Física da FEF-UFG. Ao mesmo tempo, estes trabalhadores se sentem cada vez mais desmotivados a darem prosseguimento à carreira de professor de Educação Física neste espaço. A nosso ver, a precarização e desvalorização do trabalho são decisivas para esta tendência, como explicaremos adiante.

Em segundo lugar aparece o campo de saúde com a maior quantidade de egressos atuando profissionalmente como professores de Educação Física. As próprias origens históricas da Educação Física já se apresentavam com uma relação intrínseca com a saúde, principalmente através das diferentes ginásticas europeias ${ }^{10}$. Atualmente, embora outros campos de trabalho nesse âmbito tenham crescido consideravelmente, as academias de ginástica representam o "lócus" de maior inserção de professores de Educação Física egressos da FEFUFG que atuam em espaços que tem a saúde como finalidade principal do trabalho concreto do professor de Educação Física. Reconhecemos que esse trabalho concreto está subsumido ao trabalho abstrato por não produzir simplesmente um valor de uso para o frequentador, mas também, valor de troca para a academia $^{11}$. Porém, esse fato não elimina que a saúde em aliança com a estética seja a principal finalidade da produção desenvolvida pelo trabalho do professor de Educação Física em academias de ginástica ${ }^{11}$. Dessa forma, situamos no campo da saúde os egressos que trabalham nas academias, como professores de musculação e/ou outras práticas corporais como as diferentes modalidades de ginástica, esportes, lutas, etc. Alguns dos egressos utilizam a academia para 
Furtado RP \& Santiago LP.

exercerem a função de "personal trainer", mas não necessariamente apresentam vínculo empregatício, sendo classificados em nossa pesquisa como "autônomos", mas considerados como trabalhando neste espaço. Do total de 14 pessoas categorizadas no grupo saúde, apenas uma pessoa não desenvolve suas funções em academias de ginástica, pois trabalha com ginástica laboral.

Esses resultados corroboram com as afirmaçóes de que a inserção profissional do professor de Educação Física nas academias de ginástica aumentou consideravelmente nas últimas décadas, acompanhando o grande crescimento desse setor ${ }^{8,11-12}$. Assim, elas se tornaram um campo de atuação relevante, especialmente de jovens egressos da Educação Física. Essa expansão, entre outros fatores, se deve a: própria expansão da indústria do "fitness" ${ }^{111,13}$; intensificação dos discursos de valorização das práticas corporais como fator de saúde e beleza ${ }^{14}$; além da ideologia, intensificada nas últimas décadas, de culpabilizar os próprios indivíduos pela sua condição de saúde-doença, relativizando a atuação do "Welfare State" e possibilitando a emergência no âmbito mercadológico do "Wellness" como paradigma das academias de ginástica ${ }^{15}$.
O esporte e o lazer são os campos de trabalho com menor atuação dos egressos. Categorizamo-los na TABELA 1 como "outros ligados à Educação Física (EF)", situando nessa categoria aqueles que trabalham com projetos em associaçôes filantrópicas, clubes recreativos, com iniciação esportiva e clubes de treinamento esportivo especializado.

Dentro do quantitativo de pessoas (20\%) que trabalham em áreas não diretamente relacionadas com a Educação Física ${ }^{\mathrm{e}}$, localizamos egressos atuando em instituiçôes como polícias federal e militar, corpo de bombeiros, Secretarias de Estado, além de administração de empresas privadas como proprietários e empregados.

Além de questionar a respeito do atual local de trabalho, cujas respostas foram apresentadas na TABELA 1, entendemos que uma análise de locais onde os egressos já atuaram profissionalmente desde quando terminaram o curso nos auxiliaria na constituição do perfil de sua inserção inicial no trabalho. A TABELA 2, nesse sentido, apresenta os locais de trabalho em que os egressos tiveram inserção após a formação, abrangendo todas as suas experiências profissionais até o momento da pesquisa. Essa sistematização partiu de uma questão objetiva do questionário aplicado aos egressos.

TABELA 2 - Locais em que já trabalharam após a formação inicial.

\begin{tabular}{|c|c|c|c|c|c|}
\hline Áreas & & \multicolumn{2}{|l|}{ Locais de trabalho } & \multicolumn{2}{|c|}{ Total } \\
\hline \multirow{3}{*}{ Saúde } & & Academia & & 23 & $20 \%$ \\
\hline & & "Personal trainner" & & 13 & $11 \%$ \\
\hline & & Ginástica laboral & & 5 & $4 \%$ \\
\hline \multirow{3}{*}{ Escola } & & Escola pública & & 21 & $18 \%$ \\
\hline & & Escola particular & & 17 & $15 \%$ \\
\hline & & & Total & 38 & $33 \%$ \\
\hline \multirow{6}{*}{$\begin{array}{l}\text { Outros relacionados } \\
\text { com a Educação Física }\end{array}$} & \multirow{2}{*}{ Esporte } & Escolinhas de iniciação esportiva & & 8 & $7 \%$ \\
\hline & & Empresas que prestam serviços relacionados a Educação Física & & 5 & $4 \%$ \\
\hline & \multirow{4}{*}{ Lazer } & Clube recreativo & & 3 & $2 \%$ \\
\hline & & Hotel & & 1 & $2 \%$ \\
\hline & & Associaçóes filantrópicas / comunitárias & & 3 & $2 \%$ \\
\hline & & & Total & 27 & $23 \%$ \\
\hline \multirow[t]{2}{*}{ Ensino superior } & & Universidade pública (EAD) & & 4 & $3 \%$ \\
\hline & & & Total & 4 & $3 \%$ \\
\hline
\end{tabular}


Em relação aos locais e funçôes que já desempenharam após a formação inicial observa-se quadro semelhante ao exposto na tabela anterior que diz respeito aos atuais espaços de trabalho, ou seja, escolas e academias/"personal trainer" apresentam as maiores quantidades. Além disso, essa tabela acrescenta que dos 12 participantes da pesquisa que atualmente trabalham em locais náo relacionados com a Educação Física, apresentados na tabela anterior, seis nunca trabalharam na área.

Em contrapartida aos dados apresentados nestas duas tabelas, as expectativas profissionais quando ingressaram no curso de Educação Física eram as seguintes: $36 \%$ gostariam de trabalhar em áreas relacionadas à saúde; $33 \%$ com treinamento esportivo; $37 \%$ com ensino básico; $9 \%$ com ensino superior; e 9\% com lazer (práticas recreativas); e também 9\% não sabiam ao certo qual seria o campo de atuação. Quando questionados se as expectativas antes do curso continuam as mesmas hoje, $41 \%$ afirmaram que sim enquanto $59 \%$ afirmaram que não.

O elevado percentual de egressos que informaram saúde e treinamento esportivo como expectativas profissionais quando ingressaram no curso nos remete à importância em se esclarecer que o foco de um curso de Licenciatura é a formação para a educação básica. A pouca maturidade dos vestibulandos e a falta de informação a esse respeito pode ser uma das explicaçóes para esse elevado percentual. Cabe ressaltar que até o ano de 2009, no Estado de Goiás, a Licenciatura era a única opçấo presente em instituiçóes públicas para o interessado em cursar Educação Física. A FEF-UFG abriu um curso na modalidade Bacharelado no ano de 2009 , mas os egressos que responderam aos questionários nesta pesquisa concluíram seu curso de Licenciatura em Educação Física em 2008, 2009 ou 2010.

Além disso, ao compararmos essas informações com aquelas das TABELAS 1 e 2 , chama atençáo a disparidade entre as expectativas com o treinamento esportivo e a inserção quase nula nesse campo de trabalho. Na opinião dos egressos, o projeto de formação da FEF-UFG não contribui de forma significativa para o trabalho neste campo. As respostas dos participantes (P) P-16 e P-10 são representativas da percepção de muitos dos egressos em relação aos conflitos entre a formação na FEF-UFG e suas perspectivas iniciais.
Como minhas expectativas eram de atuar na área de treinamento esportivo ou na área de personal training, a contribuição oferecida pela faculdade foi mínima, visto que estes conhecimentos são pouco contemplados em seu currículo se comparados com os outros conhecimentos vinculados com a área da pedagogia, da filosofia, da psicologia, da sociologia etc (P-16).

A faculdade forneceu apenas conhecimentos básicos e muito superficiais voltadas à área inicialmente almejada, além de estimulo mínimo para a atuação profissional fora do ambiente escolar, portanto, a contribuição foi insuficiente, não dando segurança, conhecimento e/ou instruçôes suficientes para a atuação profissional nestes ambientes (P-10).

Esta característica do currículo também é confirmada por aqueles que desde o início pretendiam atuar na escola.

Como meu objetivo sempre foi trabalhar em escolas a formação acadêmica contribuiu muito, [...] acredito que o curso serviu muito mais a quem tinha vontade de trabalhar no campo escolar do que na área do fitness, por conta do seu currículo e da concepção de Educação Física que a UFG tem (P-39).

Entretanto, as características de nossa pesquisa náo nos possibilita afirmar que a formação inicial determinou os locais de atuação dos egressos, embora provavelmente exerça influencia. Os dados apresentados acima apontam mudanças significativas entre as expectativas dos sujeitos quando ingressaram no curso com as suas expectativas atuais. Porém, não nos permitem concluir se essa mudança se deu principalmente pelo papel da formação inicial ou pelas características da realidade do trabalho encontradas pelos egressos.

Assim, entendemos que a tendência encontrada nos egressos de culpabilizar a formação inicial pela pouca oportunidade de trabalho nos campos de intervenção relacionados com o treinamento esportivo deve ser contraposta com a própria dinâmica e característica atual do mundo do trabalho, com as características de suas ofertas de emprego no mercado de trabalho. Nessa perspectiva analisamos a TABELA 3: 
TABELA 3 - Vínculo empregatício nas ocupações profissionais.

1. 0 número superior ao quantitativo de participantes $(n=46)$ se deve à possibilidade de respostas múltiplas. 2. Desconsideramos na análise o participante desempregado.

\begin{tabular}{|c|c|c|c|c|c|c|}
\hline \multirow{2}{*}{ Vínculo empregatício } & \multicolumn{2}{|c|}{ Atua na EF } & \multicolumn{2}{|c|}{ Fora da EF } & \multicolumn{2}{|c|}{ Total } \\
\hline & $\mathbf{n}$ & $\%$ & $\mathbf{n}$ & $\%$ & $\mathbf{n}$ & $\%$ \\
\hline Servidor público & 16 & $30 \%$ & 7 & $58 \%$ & 23 & $35 \%$ \\
\hline Empregado de empresa privada com carteira assinada & 18 & $33 \%$ & 3 & $25 \%$ & 21 & $32 \%$ \\
\hline Empregado de empresa privada sem carteira assinada & 7 & $13 \%$ & 1 & $8 \%$ & 8 & $12 \%$ \\
\hline Autônomo & 6 & $11 \%$ & - & - & 6 & $9 \%$ \\
\hline Contrato temporário & 4 & $7 \%$ & - & - & 4 & $6 \%$ \\
\hline Bolsista & 3 & $6 \%$ & - & - & 3 & $4 \%$ \\
\hline Proprietário de empresa & - & - & 1 & $8 \%$ & 1 & $2 \%$ \\
\hline
\end{tabular}

A maior parte dos sujeitos da pesquisa ou são servidores públicos ou trabalham com carteira assinada, conforme observado na TABELA 3. Nesta pesquisa, os servidores públicos estão na escola: na rede estadual de ensino de Goiás e nas redes municipais de educação de Goiânia e Aparecida de Goiânia. Apenas conseguiram trabalhar nesses espaços porque a dinâmica do mercado de trabalho apresentou a oferta de concursos públicos de 2008 a 2010, anos de formação dos egressos. Nesse período, quatro concursos públicos para estas redes de ensino foram realizados. Em contrapartida, o trabalho com esporte na iniciação ou no rendimento, com a saúde ou com o lazer, não apresentou nenhum concurso público realizado pelos órgãos Estaduais ou Municipais nesse mesmo período. Cinquenta e oito por cento (58\%) dos que náo trabalham com Educação Física também são estatutários, o que evidencia a mesma questão. Esses dados reforçam que a oportunidade de trabalho proporcionada pelas ofertas do mercado é um importante determinante do local de atuação.

Os trabalhos com carteira assinada concentram-se nas academias e instituiçóes escolares privadas, o que reflete a pouca oferta de emprego, atualmente, por parte de empresas privadas nos âmbitos da iniciação ou treinamento esportivo e do lazer.

A maioria dos autônomos, cinco, trabalha atualmente como "personal trainer" e apenas um deles trabalha com organização de eventos. $\mathrm{O}$ trabalho como autônomo é uma tendência da atual organização do mundo do trabalho, cujas ideologias da empregabilidade e empreendorismo são importantes características. Essa tendência também atinge a Educação Física, como mostra o crescimento dos campos da Educação Física no âmbito não escolar diante o reordenamento do mundo do trabalho ocorrido nas últimas décadas?

\section{Da precarização à frustração: as condições objetivas e o desestímulo com a carreira}

Quando perguntamos aos sujeitos da pesquisa se seus empregos atuais satisfazem suas necessidades, chama-nos a atenção uma quantidade significativa de "nãos" (30\% das respostas). Além disso, como resposta a outra questão, o quantitativo referente a $65 \%$ dos egressos afirma não apresentar mais interesse em trabalhar na área da Educação Física. Corroborando com esta condição, muitos outros indicam certa indecisão em suas respostas, seria o "em parte sim, em parte não". Em quase todos os casos está demonstrada a insatisfação com as condiçóes objetivas de trabalho, cujas determinações são internas e externas ao "lócus" de atuação. Dentro desse contexto, os sujeitos associam o tipo de trabalho desempenhado, o público alvo, o salário, a carga horária e as relaçóes de trabalho para desenharem suas justificativas.

De forma geral, as condiçóes nas quais se realiza o trabalho docente exprimem um estado de precarização que não é exclusivo desta categoria profissional. A partir das informaçóes coletadas nesta pesquisa, concluímos que há um forte nexo entre as condiçôes objetivas de trabalho e subjetivas de decisôes de permanência ou saída, aspecto que será exposto mais à diante. Estudo relacionado à Síndrome do Esgotamento Profissional (SEP) de professores de Educação Física apresenta compreensão com perspectiva semelhante ${ }^{16}$. Os autores analisaram que a sobrecarga de trabalho se constitui em uma das variáveis fundamentais para o esgotamento profissional, pois as características do ambiente de trabalho podem desencadear um tipo de sofrimento mental. $\mathrm{Na}$ mesma perspectiva, outro estudo que analisa desistência e resistência no processo de trabalho docente, considera que a fonte de maior sofrimento 
dos educadores é a "desvalorização do seu espaço de trabalho, de sua atividade e de si mesmos"17 (p.80).

A sobrecarga de trabalho associada à baixa remuneração é evidenciada pelos participantes da pesquisa como um dos principais determinantes de suas insatisfações com o trabalho na Educação Física. Sessenta e um por cento (61\%) deles trabalham em mais de um local. Geralmente esses locais estão ligados à mesma especificidade, por exemplo: mais de uma escola ou mais de uma academia, embora também existam aqueles que estão vinculados conjuntamente às escolas e academias; escolas, academias e empresas fora da Educação Física. Dos 17 sujeitos que trabalham em apenas um lugar, nove deles (53\%) não trabalham com Educação Física. Mas quando analisamos apenas dentre os que trabalham com Educação Física percebemos que oito trabalham apenas em um local e 23 trabalham em mais de um local.

TABELA 4 - Quantidade de locais onde atuam profissionalmente.

\begin{tabular}{lcccccc}
\hline \multirow{2}{*}{ Frequência } & \multicolumn{2}{c}{ Educaçáo Física } & \multicolumn{2}{c}{$\mathbf{n}$ Outros locais } & \multicolumn{2}{c}{ Total } \\
& Qtd & \% & Qtd & \% & Qtd & \% \\
\hline Apenas 1 local & 8 & $26 \%$ & 9 & $75 \%$ & 17 & $40 \%$ \\
Mais de 1 local & 23 & $74 \%$ & 3 & $25 \%$ & 26 & $60 \%$ \\
Total & 31 & $100 \%$ & 12 & $100 \%$ & 43 & $100 \%$ \\
\hline
\end{tabular}

O quantitativo acima não representa $100 \%$ dos questionários, pois desconsideramos os que são apenas bolsistas de cursos de mestrado e o desempregado, tendo assim $n=43$.
A carga horária semanal para aqueles que trabalham nos campos relacionados à Educação Física possui a média de 40 horas. Esta seria a carga horária "oficial" de trabalho. No entanto, principalmente aqueles que atuam no ensino básico, afirmam que as atividades laborais consomem também seus momentos que seriam destinados ao lazer e outros espaços de convívio social.

As falas citadas abaixo, dos participantes P-22, P-32 e P-43, exprimem bem a relação tênue entre a extenuante carga horária, a baixa remuneração e o sofrimento no trabalho. A média salarial obtida na somatória das remuneraçôes declaradas é de $\mathrm{R} \$$ $1.788,11$. Baixa se comparada à média dos que não trabalham com Educação Física e apresentam uma carga horária inferior (média de 32 horas semanais), com o salário médio equivalente a $\mathrm{R} \$ 2.538,18$.

Acredito que as minhas condições de trabalho não suprem minhas necessidades objetivas e nem subjetivas. Meu salário não paga todas as minhas contas, meus cursos de pós graduação, plano de saúde privado (já que não se pode contar com o IPASGO), combustível, alimentação e tampouco lazer. [...] E quanto às necessidades subjetivas acredito que não são supridas, pois o nosso trabalho enquanto professores nos ocupa qualquer possibilidade de tempo livre com planejamento de aula, pesquisa, correção de provas e trabalhos etc, o que acaba nos tornando escravos do trabalho (já que devido ao salário, necessitamos de uma carga mais extensa) e nos privando de acesso a lazer, ócio e convívio social (P-32).
A necessidade objetiva é o dinheiro para me sustentar. Acredito que pela minha atual jornada de trabalho, não sou bem remunerada, portanto não atendem minhas necessidades. Por necessidades subjetivas, entendo ser a minha auto-estima e felicidade no que faço. $\mathrm{O}$ trabalho que atualmente realizo não atende isto (P-43).

Já há alguns meses entendi que aprendi a gostar da idealização romantizada do fato de ser professor, do lecionar... $\mathrm{Na}$ concretude, repleta de opressões cotidianas, não existe (pelo menos pra minha pessoa) a possibilidade de sentimento de realização profissional. Tentando responder ao "por quê”, gostaria de citar: Alunos não suscetíveis ao aprendizado; Estrutura física precária (materiais, quadra, sala de aula, pátio... escola); Gestão (muitas vezes) suserana; Colegas de trabalho (professores) descompromissados;Salário ridículo, pífio. Tinha expectativa de que meu salário fosse suficiente para me dar uma vida digna, feliz e isto com o salário de professor em Goiás torna-se impossível [...] Não estou conseguindo aceitar bem o fato de que meu trabalho contribui, na melhor das hipóteses, com alguns lampejos sobre alguns alunos... Isto me parece muito insuficiente, frustrante! (P-22).

$\mathrm{O}$ desgaste se relaciona com a necessidade de obtenção de condiçóes dignas de vida. Muitas vezes os professores se submetem a uma sobrecarga de trabalho em busca de uma garantia mínima de rendimentos que atendam as suas necessidades. $\mathrm{O}$ trabalho se apresenta para o sujeito como um sofrimento necessário, 
que o faz mover-se ou acomodar-se. Assim, nesse trabalho alienado, raramente é possível se reconhecer nos resultados de seu trabalho, dificultando as expectativas em consolidar e vislumbrar uma carreira.

Neste mesmo sentido, Lapo e Bueno citados por SANTOS et al. ${ }^{18}$, analisaram como "os professores mostram-se mais preocupados em despender suas energias em defesa própria (um conformismo vinculado à sua estratégia de sobrevivência no ensino) do que abertos a novas experiências e aprendizagens" (p.151). É o que Santini e Molina Neto ${ }^{16}$ denominam como "desinvestimento pedagógico" ou "abandono do trabalho docente", no mesmo sentido que em geral apontam as teorias sobre o "abandono da carreira docente".

Para além do salário e da carga horária, chamam a atenção outras avaliaçóes a respeito da desvalorização que estão submetidos os egressos. Em geral, eles apontam limitaçôes nas suas possibilidades de intervenção profissional pela desvalorização da educação e da Educação Física. A situação definida por muitos dos participantes como "choque de realidade", também desencadeia frustração e desestímulo. SANTos et al. ${ }^{18}$ identificaram essa mesma característica ao pesquisarem de modo biográfico três professores de Educação Física que trabalham em escolas.

\section{Perspectivas de desenvolvimento da carreira}

Os egressos, a partir de resposta a uma pergunta aberta do questionário, percebem as possibilidades de construção da carreira em Educação Física em uma perspectiva bastante negativa. A análise de conteúdo das respostas nos apresentou que apenas seis dos 46 sujeitos da pesquisa (13\%), mostraram interesse em seguir carreira sem nenhum tipo de ressalvas, mostrando boas perspectivas para o desenvolvimento profissional na Educação Física. Por outro lado, 19 (41\%) afirmam não querer, de forma alguma, seguir carreira com a Educação Física. Algumas falas elucidam ao evidenciar a pretensão em buscar outros espaços de trabalho, fora da Educação Física:

Não existe possibilidade, a partir do momento em que as condiçôes objetivas me permitirem, abandono a carreira (o que deve acontecer muito em breve) (P-22).
Apenas após ter um bom emprego em outra área com um bom salário posso pensar em construir algum negócio próprio na área, como academia, escola de iniciação esportiva, etc. Se nada der certo, viro professor de Educação Física (P-36).

Atualmente meu interesse é ingressar em algum cargo público que possibilitasse ter uma maior remuneração e maior tempo para as atividades pessoais. Preciso mesmo é "respirar" fora da escola, fora das frustrações do trabalho nesta. E, a partir de então, conseguir refletir em qual profissão eu poderia contribuir melhor comigo e com aqueles a qual meu serviço fosse destinado (P-15).

Percebemos a partir dos depoimentos que a inserção no trabalho está bastante caracterizada pela falta de valorização, pelos baixos salários e por procura a melhores oportunidades de emprego. Esses aspectos aliados ao não reconhecimento e frustração com o trabalho, oriundos do seu caráter alienado como explicado anteriormente, leva-os a um distanciamento da profissão com uma expectativa de abandono da mesma.

Há ainda aqueles que vislumbram a construção de uma carreira em Educação Física, mas apenas a partir de outras condiçóes, possibilidade citada por $21 \mathrm{dos}$ egressos (48\%). As duas condiçôes apresentadas dentro desta categoria foram: possibilidade de seguirem uma carreira acadêmica, totalizando 11 respostas; modificaçóes no próprio local de trabalho atual, totalizando 10 respostas. As respostas selecionadas exemplificam a percepção desta última categoria.

Construir uma carreira na área é exatamente minha pretensão. Gostaria muito de poder continuar no ensino básico e gostaria que houvesse condições materiais para isso, mas devido à precarização da carreira docente, acabo por pretender também o ensino superior, área que também me encanta, mas que não substitui a relevância do trabalho na escola (P-34).

Ainda, sim na Escola Pública, mas gostaria de ficar lotada em uma só instituição de ensino, ao invés de três para cumprir carga horária ( $\mathrm{P}-20)$.

Ainda como forma de compreendermos melhor a perspectiva com o desenvolvimento da carreira, perguntamos aos egressos com o que gostariam de trabalhar. Obtivemos os seguintes resultados: 
TABELA 5 - Local/ Atividade que gostaria de trabalhar.

\begin{tabular}{lcc}
\hline Local/atividade & N & \% \\
\hline Ensino superior & 11 & $24 \%$ \\
Escola & 9 & $19 \%$ \\
Concurso fora da EF & 7 & $16 \%$ \\
Saúde & 3 & $7 \%$ \\
Não tem preferência & 3 & $7 \%$ \\
Proprietário de empresas & 2 & $4 \%$ \\
Treinamento esportivo & 1 & $2 \%$ \\
Lazer & 1 & $2 \%$ \\
Já estou onde gostaria & 9 & $19 \%$ \\
Total & 46 & $100 \%$ \\
\hline
\end{tabular}

Temos aqui uma confirmação de que continuar a seguir carreira na Educação Física faz parte das expectativas futuras de trabalho da maioria dos egressos, porém, a atuação no ensino superior é o principal local vislumbrado. Ou seja, aquilo que se apresenta aparentemente como perspectiva de futuro na carreira em Educação Física, na verdade, está preponderantemente localizado na busca pelo trabalho no ensino superior. O que em uma análise mais atenta reforça a desmotivaçáo com o exercício da profissão de Educação Física nos ambientes de educação formal, especificamente na educação básica e nos ambientes de educação náo formal: saúde, lazer, esporte e outros. Auxilia esse entendimento a comparação com os resultados indicados anteriormente, logo abaixo da TABELA 2. Percebemos que o interesse pelo trabalho no ensino superior era de apenas $9 \%$ ao iniciarem o curso, esse interesse aumenta significativamente para $24 \%$ quando os egressos concluem o curso e se inserem no mercado de trabalho. Essa situação é confirmada por respostas como as que seguem e afirmam a perspectiva de trabalho no ensino superior aliada à possibilidade de melhores condições de trabalho $\mathrm{e}$ de um suposto "status":

Gostaria de trabalhar com melhores condições objetivas principalmente em relação a valorização e salários dignos. Gostaria também de me inserir em uma instituição de ensino superior, o que pretendo tentar ao termino de minha especialização e ingresso no mestrado de educação ou dança (P-27).

Gostaria de estar exatamente onde estou, mas gostaria que as condiçōes objetivas fossem melhores. Gostaria também de me inserir em uma instituição de ensino superior, o que pretendo tentar tão logo termine a especialização (P-32).
Gostaria de trabalhar com o ensino superior, pois me sinto mais a vontade neste tipo de relação professor-aluno e as possibilidades de pesquisa, grupos de estudos, condições de trabalho e reconhecimento profissional que a Universidade oferece (P-44).

Percebe-se que os altos índices de insatisfação não dizem tanto respeito às características específicas da Educação Física como campo de pesquisa e intervenção. Ao contrário, as baixas perspectivas para o desenvolvimento da profissão estão diretamente relacionadas com as condiçôes objetivas de trabalho que criam uma condição de frustração, desestímulo e desistência.

Cabe ressaltar da TABELA 5 que dos nove egressos que afirmam já trabalhar onde gostariam, sete não atuam na Educação Física, ou seja, apenas dois dos que afirmam estar trabalhando onde gostariam estão na Educação Física. Esse número chama muito a atenção e confirma que de fato o local de trabalho não é simplesmente uma escolha subjetiva, mas está diretamente relacionado com as oportunidades de trabalho encontradas. Em outras palavras, o egresso não trabalha onde escolhe, mas sim fundamentalmente onde consegue. Os sete que afirmam estarem satisfeitos atuando fora da Educação Física, somado aos sete que afirmam o desejo de realizar concurso fora da Educação Física, totalizam 14 egressos com perspectivas de deixar este campo de atuação profissional. E, ao somar esses 14 aos 11 que pretendem trabalhar com o ensino superior, totalizam-se 25 , equivalente a $56 \%$, que não pretendem trabalhar nos âmbitos da educação básica e nos outros campos de trabalho da Educação Física, tais como esporte, lazer e saúde.

Cabe ressaltar ainda que a literatura ${ }^{1,19-20}$ aponta que os conflitos emergem em diferentes fases da carreira, especialmente no início dela. De acordo com as classificações encontradas em TARDIT e RAYMOND $^{1}$ e VERENGUER ${ }^{20}$, os sujeitos pesquisados neste estudo encontram-se na primeira fase da carreira: a fase de exploraçãoo (três primeiros anos).

A fase de exploração caracteriza-se por um momento na carreira em que a opção por ela é provisória, na qual o profissional está experimentando-a e investigando-a. Concisamente, poderíamos afirmar que nesta fase confundemse o aspecto da sobrevivência (a confrontação inicial com o real, o tateamento com o cotidiano do trabalho, as dúvidas sobre si mesmo e sobre sua competência) com o da descoberta (o entusiasmo, a exaltação por estar em situação de responsabilidade, por participar de um corpo 
profissional). Se nesta fase o profissional viveu uma experiência positiva e significativa, passará para a fase de estabilização, na qual observamos o comprometimento com a carreira e o desenvolvimento de uma identidade profissional (p.64) ${ }^{20}$.

Como foi exposto neste artigo, a maioria dos sujeitos da pesquisa não viveram uma experiência positiva e significativa, elementos fundamentais, de acordo com VERENGUER $^{20}$, para dar prosseguimento à carreira, com a estabilização de uma identidade profissional.

Percebemos que apesar dos estudos que demonstram a ampliação da oferta de serviços relacionados com a Educação Física, há ainda pouca diversidade dos locais de inserção profissional em Goiás, com concentração nas grandes áreas educação e saúde, neste último caso, especialmente em academias de ginástica. Analisamos que este fato se deve, em grande parte, à maior oferta e oportunidade de empregos nestes locais. Também ocupa lugar significativo o quantitativo de egressos que náo mais atuam na área, levados principalmente pelas maiores remuneraçóes e condiçôes de trabalho de uma forma geral. Os egressos que vislumbram a construção da carreira em Educação Física, em sua maioria, almejam o ingresso profissional no ensino superior, o que na verdade reforça a "fuga" das precárias condições de trabalho da Educação Física de uma forma geral.

As condiçóes objetivas não satisfatórias influenciam diretamente as expectativas futuras com a Educação Física, levando-os ao abandono da profissão ou a frustração e desestímulo no trabalho. É preciso considerar que os sujeitos se encontram no início de suas carreiras, confirmando os conflitos do chamado "choque de realidade". E compreender essa realidade complexa e contraditória demanda tempo, reflexão, criticidade e ações que poderão ou não ser bem sucedidas. É necessário não se equivocar com a análise que afirmaria que todos esses elementos dependem unicamente do egresso. $\mathrm{O}$ aprendizado, as escolhas profissionais e as frustraçóes com o trabalho se dão socialmente num contexto histórico, portanto, não podem ser analisadas sob um único foco, mas sim, por meio de suas múltiplas determinaçóes.

Pesquisas futuras podem aprofundar essas análises, por exemplo, investigando se há relação significativa entre a frustração do egresso e a impossibilidade de trabalhar com conteúdos que lhes agradariam mais.
Em nossa pesquisa percebemos que há egressos trabalhando em escolas como professores de dança. Será que tal situação, por limitar as possibilidades da Educação Física escolar a um único conteúdo, é relevante na frustração com o trabalho? Essa e outras questôes podem ser exploradas com maior profundidade e acrescentar reflexôes importantes ao debate.

Não foi objetivo desse trabalho, analisar a influência da proposta pedagógica da FEF-UFG na inserção e intervenção de seus egressos no mundo do trabalho. Entretanto, podemos indicar que esta se situa numa perspectiva progressista que, a nosso ver, avança no sentido de uma formação ampliada, com compromisso ético e político na transformação da sociedade. E é por isso que acreditamos que a perspectiva dos egressos em atuar na Universidade como um escape das condiçóes precárias é bastante limitada e contraditória. Afinal, quando se analisa o compromisso da formação inicial pressupóe-se que os conhecimentos e princípios ali desenvolvidos possam contribuir para efetivação de um projeto político nos próprios campos de intervenção da Educação Física. Não se efetiva um projeto político na dimensão apenas teórica. Estudos como os de Palafox ${ }^{21}$ vêm mostrando as dificuldades de materializar avanços teóricos na Educação Física brasileira, sendo necessário olhar não apenas sua prática pedagógica, mas também os sujeitos que a compóe. Neste sentido, é fundamental que os agentes da transformação, nesse caso, professores e professoras de Educaçáo Física, atinjam um grau de autonomia na intervenção profissional e na organização coletiva. Faz-se necessário, dessa forma, uma maior proximidade da Universidade com a realidade dos campos de trabalho.

Por outro lado, não é apenas essa aproximação que os resultados desta pesquisa apontam como necessária. $\mathrm{O}$ elevado percentual de alunos que indicaram interesses, ao ingressarem no curso, relacionados com o treinamento esportivo e com a saúde explicita a necessidade de aproximação da Universidade com a educação básica. Tal aproximação poderia favorecer a um maior esclarecimento ao vestibulando a respeito do foco do currículo do curso pretendido. Além disso, o próprio professor da disciplina Educação Física, pode desempenhar esse papel esclarecedor aos seus alunos no ensino médio. 


\title{
Notas
}

a. O Ministério Público Federal propôs ação civil pública, cujo processo é de n. 0013853-04.2011.4.01.3500, com a finalidade de afastar a prática de atos que possam restringir o campo de atuação dos profissionais graduados em cursos de Licenciatura em Educação Física. O Juiz Euler de Almeida Silva Júnior da Nona Vara da Seção Judiciária do Estado de Goiás da Justiça Feral decidiu em sentença ainda em vigor que: "suspendam no âmbito territorial da Seção Judiciária do Estado de Goiás, a prática de atos que possam restringir o campo de atuaçáo dos profissionais graduados em cursos de Licenciatura em Educação Física." (Disponível em: http://portal.trf1.jus.br/sjgo/).

b. Ver pareceres CNE/CES 400/2005; CNE/CES 255/2012; CNE/CES 274/2011.

c. A população da pesquisa compreendeu as seis primeiras turmas formadas no regime semestral da FEF-UFG, sendo três matutinas e três vespertinas, em cada ano indicado. Portanto, são duas turmas que se formam por ano. De acordo com informaçôes da Secretaria Acadêmica do curso, os formandos previstos nestas seis turmas totalizavam 186. A amostra de 46 egressos representa $24,7 \%$ da população total. Houve grande dificuldade de acesso aos contatos e e-mails dos envolvidos. Inicialmente procurou-se a FEF-UFG para obtenção das referidas informaçóes, no entanto, uma greve dos servidores técnico-administrativos inviabilizou a tentativa. Dessa forma, o acesso aos e-mails derivou de contatos pessoais com representantes das turmas que forneceram e-mails dos colegas.

d. A dança é um conteúdo da educação básica presente na área de linguagens, códigos e suas tecnologias. O conteúdo pode ser ministrado tanto pela disciplina Educação Física quanto pela disciplina Artes. Mas as escolas podem oferecer a disciplina dança de forma específica. No Estado de Goiás, algumas escolas públicas oferecem a disciplina Dança como componente curricular não obrigatório, para tanto, foi realizado concurso público que permitiram a candidatura de licenciados em Dança ou em Educação Física. Neste mesmo concurso foram oferecidas vagas para outras disciplinas, dentre elas a Educação Física e o candidato licenciado em Educação Física deveria optar por uma ou outra disciplina no processo seletivo. Neste concurso, foram aprovados dois licenciados em Dança e 58 licenciados em Educação Física para a disciplina Dança. Os Institutos Federais também realizam concurso especificamente para Dança e geralmente permitem a inscrição e aprovam candidatos da área de artes e da Educação Física (Licenciatura e Bacharelado).

e. Para essa questâo havia a possibilidade múltipla escolha, por isso, há também nesse grupo aqueles que trabalham com a Educação Física e ao mesmo tempo trabalham em outros lugares não relacionados á área.

\begin{abstract}
Physical Education and work: the integration of considerations regarding the professional egresses from ETF-UFG

This study aimed to analyze the initial insertion in fields of professional intervention of graduates from the Faculdade de Educação Física (FEF) of Universidade Federal de Goiás (UFG). We received replies from 46 questionnaires distributed to graduates of Physical Education classes, graduating in 2008, 2009 and 2010, which are the first three classes formed after the curriculum revision. From this research we perceive contradictions between professional expectations before and after the initial formation. We identify the school and fitness center as the main workplace of graduates. Despite being the beginning of their careers, many are already discouraged with working conditions. However, some still envision possibilities for career development, both for improving working conditions in the field of intervention, as well as employment opportunities and higher education teachers.
\end{abstract}

KEY WoRDS: Career; Professional activity; School; Fitness center. 


\section{Referências}

1. Tardif M, Raymond D. Saberes, tempo e aprendizagem do trabalho no magistério. Educ Soc. 2000;21:209-44. Disponível em: http://redalyc.uaemex.mx/src/inicio/ArtPdfRed.jsp?iCve=87313697013.

2. Gramsci A. Cadernos do cárcere. Rio de Janeiro: Civilização Brasileira; 2001. v.4

3. Castel R. As metamorfoses da questáo social: uma crônica do salário. Petrópolis: Vozes; 2008.

4. Sennett R. A corrosão do caráter: consequências pessoais do trabalho no novo capitalismo. Rio de Janeiro: Record; 2003.

5. Gil AC. Métodos e técnicas da pesquisa social. São Paulo: Atlas; 1989

6. Minayo MC. Pesquisa social: teoria, método e criatividade. Petrópolis: Vozes; 2004.

7. Bardin L. Análise de conteúdo. Lisboa: Edições 70; 1977.

8. Quelhas AA. Trabalhadores de educação física no segmento fitness: um estudo da precarização do trabalho no Rio de Janeiro [tese]. Marília (SP): Universidade Estadual Paulista; 2012.

9. Nozaki HT. Educação física e o reordenamento do mundo do trabalho: mediaçóes da regulamentação da profissão. (tese). Niterói (RJ): Universidade Federal Fluminense; 2004.

10. Soares CL. Educação física: raízes européias e Brasil. 4a ed. Campinas: Autores Associados; 2007.

11. Furtado RP. O não-lugar do professor de educação física em academias de ginástica [dissertação]. Goiânia (GO): Universidade Federal de Goiás, Faculdade de Educação; 2007.

12. Coelho Filho CAA. O discurso do profissional de ginástica em grandes academias no Rio de Janeiro [dissertação]. Rio de Janeiro (RJ): Universidade Gama Filho; 1998.

13. Mascarenhas F, Pasquali D, Niterói R. A indústria do fitness e seu desenvolvimento desigual: um estudo sobre as academias de ginástica na cidade de Goiânia. Pensar Prát. 2011;14:1-15. Disponível em: http://www.revistas.ufg.br/ index.php/fef/article/view/12311.

14. Baptista TJR. Procurando o lado escuro da Lua: implicaçóes sociais da prática de atividades corporais realizadas por adultos em academias de ginástica de Goiânia [dissertação]. Goiânia (GO): Universidade Federal de Goiás, Faculdade de Educação; 2001.

15. Furtado RP. Do fitness ao wellness: os três estágios de desenvolvimento das academias de ginástica. Pensar Prát. 2009;12: 1-11. Disponível em: http://www.revistas.ufg.br/index.php/fef/article/view/4862.

16. Santini J, Molina Neto V. A síndrome do esgotamento profissional em professores de educaçáo física: um estudo na rede municipal de ensino de Porto Alegre. Rev Bras Educ Fís Esporte. 2005;19:209-22. Disponível em: http://www. revistasusp.sibi.usp.br/scielo.php?script=sci_arttext\&pid=S1807-55092005000300004\&lng=pt\&nrm=iso\&tlng=pt.

17. Caldas AR. Desistência e resistência no trabalho docente: um estudo das professoras e professores do ensino fundamental da rede municipal de educação de Curitiba [tese]. Curitiba (PR): Universidade Federal do Paraná; 2007.

18. Santos NZ, Bracht V, Almeida FQ. Vida de professores de educaçáo física: o pessoal e o profissional no exercício da docência. Movimento. 2009;15:141-65. Disponível em: http://seer.ufrgs.br/Movimento/article/view/3067.

19. Folle A, Farias GO, Boscatto JD, Nascimento JV. Construção da carreira docente em educação física: escolhas, trajetórias e perspectivas. Movimento. 2009;15:25-49. Disponível em: http://seer.ufrgs.br/Movimento/article/view/3014.

20. Verenguer RCG. Mercado de trabalho em educação física: significado da intervençáo profissional à luz das relaçôes de trabalho e da construção da carreira [tese]. Campinas (SP): Universidade Estadual de Campinas, Faculdade de Educação Física; 2003.

21. Palafox GHM. PCTP: por que está sendo difícil implementar propostas críticas de ensino da educação física na escola? In: Palafox GHM, et al, organizadores. Planejamento coletivo do trabalho pedagógico - PCTP: a experiência de Uberlândia. Uberlândia: Casa do Livro; 2002. p.11-24.

\begin{tabular}{r|r} 
ENDEREÇo & \\
Roberto Pereira Furtado & \\
Faculdade de Educação Física e Dança & Recebido para publicação: 05/04/2013 \\
Universidade Federal de Goiás & 1a. Revisão: 26/03/2014 \\
2a. Revisão: 30/09/2014 \\
$\begin{aligned} \text { Rod. Goiânia-Nerópolis km 12 - Campus Samambaia } \\
\text { e-mail: cremerroberto@hotmail.com }\end{aligned}$ & $\begin{aligned} \text { Aceito: 31/12/2014 } \\
\end{aligned}$ \\
\end{tabular}

336 • Rev Bras Educ Fís Esporte, (São Paulo) 2015 Abr-Jun; 29(2):325-36 